\title{
VARIAÇÃO TEMPORAL DA ESTRUTURA DOS BOSQUES DE MANGUE DE SUAPE-PE APÓS A CONSTRUÇÃO DO PORTO ${ }^{1}$
}

\author{
Marta Maria de Almeida Souza ${ }^{2}$ \\ Everardo V. S. B. Sampaio ${ }^{3}$
}

Recebido em 3/2/1999. Aceito em 9/3/2001

\begin{abstract}
RESUMO - (Variação temporal da estrutura dos bosques de mangue de Suape-PE após a construção do porto). Para acompanhar o impacto da implantação do porto de Suape, PE, na estrutura da vegetação do mangue, foram comparados dados de 1988 e 1995, em seis áreas pouco antropizadas (PA), quatro muito antropizadas (MA), três em regeneração inicial (RI) e duas em regeneração antiga (RA). Em cada área foram alocadas seis parcelas de $10 \mathrm{x}$ $10 \mathrm{~m}$ e medidos altura das plantas e diâmetro dos caules. Quatro espécies foram encontradas, sem um padrão de zonação definido: Rhizophora mangle L., Laguncularia racemosa (L.) Gaertn., Avicennia schauerianna Stapf. \& Leechman e Avicennia germinans L. Conocarpus erecta L. apareceu apenas na transição mangue - restinga. A distribuição das espécies não teve mudanças marcantes entre 1988 e 1995 e nem diferenças nas situações de antropização. As áreas PA tiveram uma diversidade grande de estrutura (densidade, 917-5683 plantas/ha; área basal, 12,7-60,8m²/ha; diâmetros médios e máximos, 5,6-22,4 e 12-36cm; alturas médias e máximas, 6,7-16,3m e 10-18m) e mudanças, no período, indicando que tinham sofrido cortes seletivos, já sem marcas visíveis. Sem o acompanhamento no tempo, não seriam bom padrão de referência. As áreas MA tinham sinais visíveis de corte seletivo e reduções na densidade de plantas com diâmetro $>10 \mathrm{~cm}$ e nas áreas basais. As áreas em regeneração após aterro ou alagamento, antes (RA) e depois de 1988 (RI), tinham alturas, diâmetros e áreas basais inferiores tanto aos de PA e MA, mas as de RA tinham as maiores densidades (7150-11850 plantas/ha). Portanto, oito anos não foram suficientes para sua recuperação.
\end{abstract}

Palavras-chaves - manguezal, estrutura, regeneração, impacto ambiental, Brasil.

\begin{abstract}
Changes on the vegetation structure of mangroves after the construction of the Suape port (PE, Brazil). To monitor the impact of the Suape (PE, Brazil) port construction on the vegetation structure of the mangroves of the area, data from 1988 and 1995 were compared, using six little disturbed sites (LD), four sites undergoing selective logging (SL), three old regeneration sites (OR) and two new regeneration sites (NR). Six plots $10 \mathrm{x} 10 \mathrm{~m}$ were established in each site, all plants found in those in plots had for their height and stem diameter measured. Four species were found without a well defined distribution pattern: Rhizophora mangle L., Laguncularia racemosa (L.) Gaertn., Avicennia schauerianna Stapf. \& Leechman and Avicennia germinans L. Conocarpus erecta L. was present in the mangrove - sand coastal transition area. The species distribution showed no marked change between 1988 and 1995 and no differences related to disturbance situation. LD sites had a large structural diversity (density, 917-5683 plant/ha; basal area, 12.7-60.8 $\mathrm{m}^{2} / \mathrm{ha}$; average and maximum diameter, 5.6-22.4 and 12-36 cm; average and maximum height, $6.7-16.3$ and $10-18 \mathrm{~m}$ ) and their changes during the period indicate that selective cutting had
\end{abstract}

Parte da dissertação de Mestrado em Botânica, Universidade Federal Rural de Pernambuco - UFRPE. Com bolsa do CNPq

Rua Monsenhor Agostinho, 358, Vila Pery, CEP 60730-710, Fortaleza, CE

Departamento de Energia Nuclear, UFPE, CEP 50740-540, Recife, PE 
occurred, but no signs of that could be detected. Without periodical monitoring, they would not provide an adequate reference pattern. SL sites had visible logging marks and decreases in the densities of plants with diameter $>10 \mathrm{~cm}$ and in basal areas. Regeneration sites after flooding or filling up with earth, before (OR) and after 1988 (NR), had height, diameter and basal area lower than those of LD and SL, but OR had the highest density (7150-11850 plant/ ha). Therefore, 8 years were not enough for recovery.

Key words - mangrove, structure, regeneration, environmental impact, Brasil.

\section{Introdução}

Entre os recursos naturais, as áreas de manguezais representam um patrimônio importante, uma vez que são consideradas zonas de elevada produtividade biológica e fonte de recursos pesqueiros. Este sistema funciona como uma unidade integrada, sendo a vegetação a principal responsável pela dinâmica produtiva dos estuários tropicais e áreas adjacentes. A literatura tem muitas descrições qualitativas das respostas dos mangues aos tensores. No entanto, existem poucos dados quantitativos sobre a sensibilidade dos mangues a intensidade e durações conhecidas dos tensores naturais e antrópicos. Dos 550 trabalhos listados na bibliografia, sobre manguezais brasileiros, (Schaeffer-Novelli 1993) indo de 1914 a 1986, apenas 5\% faziam referências a dados estruturais e eles ocorriam em maior proporção nos cinco últimos anos.

Em estudos recentes (Rao et al. 1987; Cintrón 1987; Silva 1991; Robertson et al. 1991; Azariah et al. 1992; Amarasingle \& Balasubramaniam 1992; Clarke \& Allaway 1993; Blanchard \& Prado 1995) têm sido utilizados parâmetros que descrevem a estrutura e funcionamento desses ecossistemas e sugerem a existência de uma variação ampla de estratégias de sobrevivência relacionadas a fatores ambientais. Se estas estratégias ou adaptações estruturais e funcionais fossem melhor entendidas, proveriam uma base para definir os princípios comuns que governam o funcionamento dos mangues.

As áreas estuarinas de Pernambuco, em 1970/71, abrangiam $250 \mathrm{~km}^{2}$ cobertos por água e $174 \mathrm{~km}^{2}$ por manguezal (Pereira 1993). Atualmente, várias destas áreas de manguezal já se encontram destruídas, principalmente por desmatamento, aterramento e introdução de substâncias poluentes advindas da indústria do açúcar e esgotos sanitários. Objetivando estudar os impactos ambientais sobre o manguezal de SuapePE, decorrentes da implantação de um porto e da infra-estrutura para um complexo industrial em 1979/80, Braga et al., (1989) analisaram as intervenções físicas ocorridas no período de 1974 a 1988. Nos quatorze anos de intervalo analisado, dos 2.874ha de manguezal inicialmente existentes, restavam 2.276ha em 1988. Os 598 ha destruídos correspondiam a $21,2 \%$ da área coberta por mangues na zona estuarina de Suape. Destes, 214ha foram aterrados por aterro hidráulico ou material argiloso oriundo de outras áreas e 384ha foram alagados, em decorrência de dragagem e inundações por represamento. Mais 27ha encontravam-se em processo de degradação, devido a uma inundação temporária, ocorrida em conseqüência de obstrução da vazão do rio Ipojuca em sua foz, quando da construção do porto. Eles caracterizaram a estrutura do manguezal em oito estações, incluindo áreas preservadas e em regeneração.

Para um maior conhecimento da resposta da vegetação dos manguezais aos impactos ambientais, realizou-se um estudo comparativo da estrutura do manguezal atualmente na área de Suape, com a descrita por Braga et al.(1989), determinando-se as modificações em cada um dos trechos estudados e analisando-se qualitativa e quantitativamente as informações observadas neste período.

\section{Material e métodos}

O litoral de Pernambuco apresenta uma extensão de 187km (Gomes 1989), incluindo o 
complexo estuarino de Suape, localizado nos municípios do Cabo e Ipojuca, entre as latitudes $8^{\circ} 20^{\prime} 00^{\prime \prime} \mathrm{S}$ e $8^{\circ} 29^{\prime} 00^{\prime \prime} \mathrm{S}$ e longitudes $34^{\circ} 56^{\prime} 30^{\prime \prime} \mathrm{W}$ e $35^{\circ} 03^{\prime} 00^{\prime \prime} \mathrm{W}$, distando cerca de $40 \mathrm{~km}$ da cidade do Recife. A área é cortada por diversos rios e riachos, com maior concentração ao sul do cabo de Santo Agostinho (Melo-Filho 1977). Antes da implantação do porto, em 1979/80, convergiam para a baia de Suape, no sentido norte-sul, os rios Massangana, Tatuoca, Ipojuca e Merepe. Os dois últimos tinham suas águas canalizadas pela extensa linha de arrecifes de arenito, interrompidas ao norte pelo cabo de Santo Agostinho. Com a formação do aterro hidráulico, onde atualmente encontra-se o terminal de tancagem de Suape, a vazão do estuário dos rios Ipojuca e Merepe foi dificultada, acarretando mudanças radicais na hidrologia local, alterando o fluxo e refluxo normais das águas.

Neumann (1991), estudando a geomorfologia e sedimentologia quaternária de Suape, comentou que, geomorfologicamente, a área pode ser dividida em três compartimentos: colinas arredondadas, rampas de colúvio e planície costeira, sendo que a última domina toda a parte sudoeste e, quase totalmente, as partes sudeste e nordeste da área. Esta planície é composta por três tipos de ambientes de deposição diferentes: ambientes de depósitos fluviais, de depósitos de mangue e de depósitos marinhos. Dentre estes, os de mangues são os que predominam, cobrindo grande parte da faixa central da área, na direção N-S.

Dados hidrológicos obtidos por Cavalcanti et al. (1980), antes da implantação do porto, permitiram a classificação do ecossistema, em três zonas: a primeira, abrangendo a baía de Suape, caracterizada como marinha costeira; a segunda, compreendendo os rios Massangana e Tatuoca, caracterizada como zona estuarina com regimes salinos polialinos, e a terceira, estuário do rio Ipojuca, com regime de salinidade variando de polialino a limnético. Após a implantação do porto, a baía de Suape continua com características marinhas, os rios Massangana e
Tatuoca apresentam altas salinidades em suas áreas mais internas, enquanto o rio Ipojuca continua polialino, porém com variações máximas e mínimas mais acentuadas e com ciclos extremamente irregulares, em consequiência da alteração do ritmo das marés (Neumann-Leitão 1994).

O clima é tropical úmido do tipo A's, segundo a classificação de Köppen, e, segundo Andrade \& Lins (1971), é pseudotropical, com um período seco entre setembro e fevereiro e outro chuvoso de março a agosto. A precipitação pluviométrica no período de 1970-1990 apresentou valor mínimo em outubro, com média de $51 \mathrm{~mm}$ e valor máximo em julho, com $396 \mathrm{~mm}$ e média total anual é de $1.814 \mathrm{~mm}$ (Neumman-Leitão 1994). As temperaturas médias anuais, médias das máximas e médias das mínimas foram $23,24 \mathrm{e} 22^{\circ} \mathrm{C}$, respectivamente. A umidade relativa do ar é bastante elevada, com médias anuais de 80 a $86 \%$.

Para a caracterização dos parâmetros fitossociológicos utilizou-se o método de parcelas múltiplas, distribuídas ao longo de estações de amostragem, por ser esta metodologia a mais difundida nos trabalhos quantitativos realizados em bosques de mangue (SchaefferNovelli \& Cintrón 1986; Pool et al. 1975; Dixon et al. 1991). Em 1995, quinze estações de amostragem foram distribuídas, em quatro tipos de situação quanto ao seu antropismo aparente: 1) seis em áreas atualmente pouco antropizadas (PA), com pouco ou nenhum sinal de corte de árvores; 2) quatro em áreas com muito antropismo (MA) atual, consistindo principalmente de corte seletivo das árvores de maior porte; 3 ) três em áreas em processo de regeneração inicial (RI), posterior a 1988, quando duas estavam sem vegetação por ter sido alagadas e uma por ter sido aterrada; e 4) duas em processo de regeneração antiga (RA), iniciado antes de 1988, quando já estavam iniciando sua recuperação. As estações foram distribuídas ao longo dos rios Ipojuca, Merepe e Tatuoca (Fig. 1) e oito delas localizadas nos mesmos pontos das 


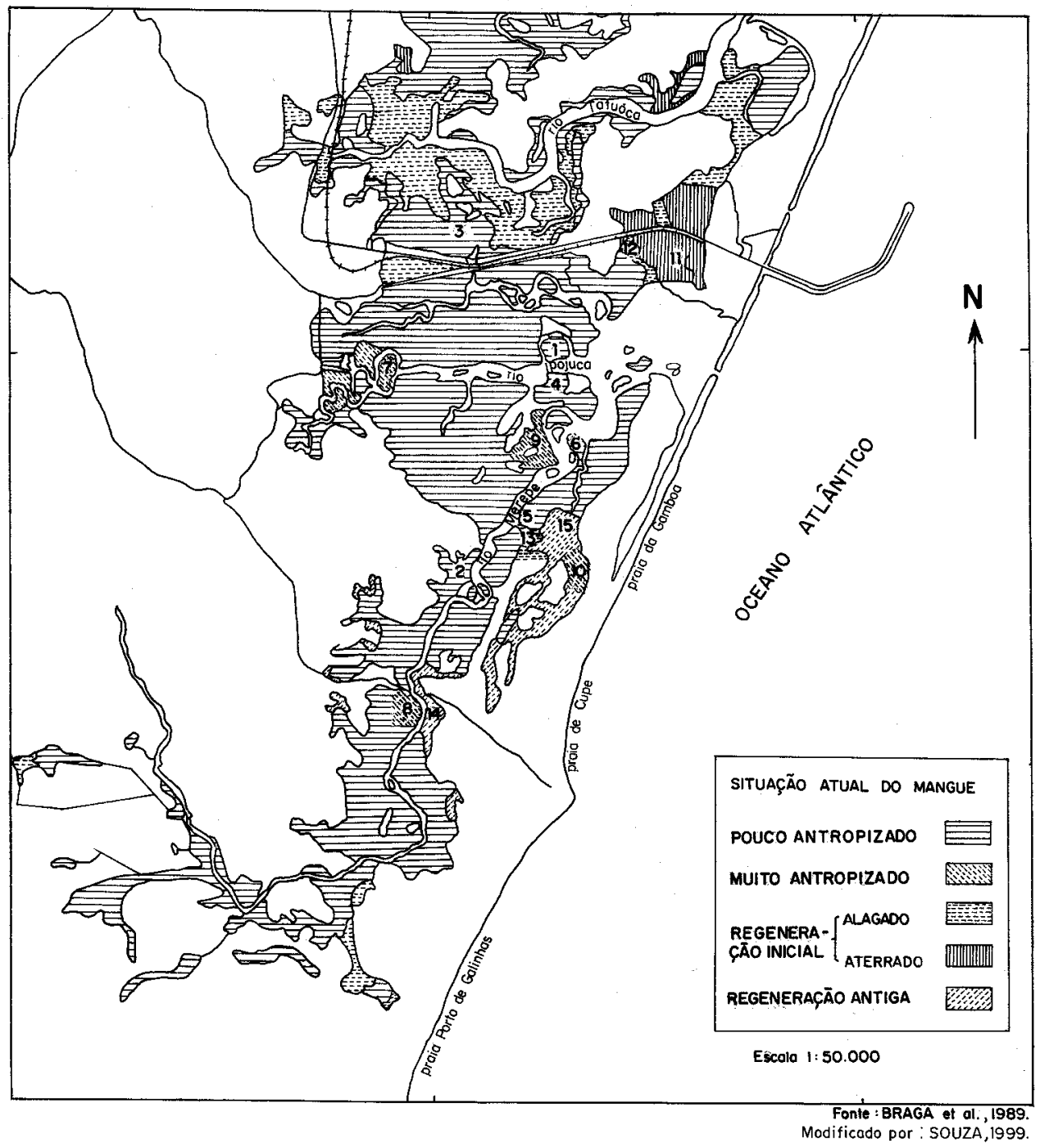

Figura 1. Localização das 15 estações de amostragem da vegetação de mangue, em Suape - PE.

estações trabalhadas por Braga et al. (1989), em 1988, tendo, na época, seis delas sido consideradas preservadas e duas em regeneração inicial. A situação das outras sete estações em 1988 foi baseada no mapa elaborado por estes autores.

Em cada estação, foram alocadas seis parcelas, divididas em dois grupos de três parcelas contíguas, cada uma com $10 \times 10 \mathrm{~m}$. As parcelas de cada grupo eram paralelas à margem do rio, ficando as do primeiro grupo a $5 \mathrm{~m}$ e as do outro grupo a $20 \mathrm{~m}$ da margem. Os cantos de cada par- cela foram marcados com estacas e a parcela delimitada com corda de náilon. Dentro de cada parcela, foram medidas todas as plantas quanto: 1) as circunferências dos caules a uma altura de 1,3m do nível do sedimento (altura do peito) para todas as espécies, exceto para $R$. mangle que teve medidas logo acima da inserção do rizóforo mais alto; e 2) as alturas totais da parte aérea das plantas, tomadas com um telêmetro Ranging optimeter - 120. Cada planta foi identificada quanto à espécie e material botânico fértil de cada es- 
pécie encontra-se tombado no herbário PEUFR da UFRPE.

Para caracterizar a arquitetura de cada fitocenose analisaram-se: 1) a distribuição de todos os indivíduos no espaço vertical, através de histogramas a intervalo fixo de $1 \mathrm{~m} ; 2$ ) a distribuição diamétrica de todos os indivíduos, através de histogramas a intervalo fixo de $3 \mathrm{~cm}$ e também separando-os em três classes: $\langle 2,5 \mathrm{~cm}$, entre 2,5 e $10 \mathrm{~cm}$, e $>10 \mathrm{~cm} ; 3$ ) a densidade total (DT, plantas/ha); e 4) a área basal total (AB, $\mathrm{m}^{2} /$ ha). Os parâmetros DT e AB foram calculados utilizando-se os programas PREPARE e PARAMS, do pacote FITOPAC de autoria do Dr. G. J. Shepherd, do Departamento de Morfologia e Sistemática Vegetal da Universidade Estadual de Campinas (UNICAMP). Os parâmetros calculados na caracterização da estrutura de abundância (Rodal et al. 1992) foram: densidade absoluta (DA, ind/ha), densidade relativa por espécie (DR, \%), freqüência absoluta por espécie (FA, \% ), freqüência total absoluta (FTA, \% ), frequiência relativa por espécie (FR, $\%)$, área basal por espécie $\left(\mathrm{AB}, \mathrm{m}^{2} / \mathrm{ha}\right)$, área basal relativa por espécie (ARe, \%) e o índice do valor de importância por espécie (IVI, \%) que é a soma da densidade, da área basal e da freqüência relativas.

Para comparação das quatro situações de antropização e das estações de amostragem dentro de cada uma destas situações foram feitas análises de variância (Statsoft 1995) dos parâmetros da arquitetura da comunidade: alturas média e máxima, diâmetros médio e máximo; densidade total; e área basal total. As seis parcelas foram consideradas como repetições de cada estação depois que uma análise prévia não encontrou diferenças significativas entre os dois grupos de parcelas localizados a 5 e $20 \mathrm{~m}$ das margens. Na comparação das situações de antropização, as estações foram consideradas como subgrupos. As comparações dentro de cada situação foram feitas com análises separadas para cada uma. As médias foram comparadas pelo teste de Tukey a $5 \%$ de probabilidade. As distribuições de alturas e de diâmetros das plantas das quatro situações foram comparadas pela prova de Kolmogorov - Smirnov para duas amostras (Siegel 1975). Foram usadas as distribuições percentuais das plantas nas classes, para eliminar as diferenças de densidade e tornar a prova mais rigorosa.

\section{Resultados e discussão}

No conjunto de todas as quatro situações de antropização (Tab. 1), foram registradas cinco espécies, pertencendo a quatro gêneros e três famílias. Em geral, o número de espécies registrado nos mangues nordestinos tem sido três ou quatro, mostrando sua baixa diversidade florística (Sampaio 1996) e entre elas estão incluídas quatro das espécies encontradas em Suape: Rhizophora mangle L., Laguncularia racemosa (L.) Gaertn., Avicennia schauerianna Stapf. \& Leechman. e Avicennia germinans L. A outra espécie registrada foi Conocarpus erecta L., presente apenas em uma única parcela da estação 12 (Tab.2) e em uma área de transição de mangue para restinga. As espécies, de um modo geral, não apresentaram um padrão de zonação definido. R. mangle apareceu com maior frequiência na franja do mangue, principalmente nas proximidades da desembocadura, sendo gradualmente substituída pelas espécies de Avicennia e/ou L. racemosa mais para o interior do continente. Resultados semelhantes foram encontrados no Maranhão (Damásio 1980), Sergipe (ADEMA 1984) e Ceará (SEMACE 1994), confirmando a semelhança dos mangues do nordeste (Cintrón \& Schaeffer-Novelli 1983).

A distribuição das espécies nas diferentes situações de antropização também não revelou um padrão definido e nem houve mudanças marcantes entre 1988 e 1995, nas densidades relativas de cada espécie, principalmente porque a maioria das estações (11) era e continuou sendo povoada exclusiva ou predominantemente por uma única espécie. Entre estas datas, no total de todas as estações, houve uma queda na participação de L. racemosa (de 93 a $83 \%$ da 
Tabela 1. Número da estação neste trabalho e no trabalho feito por Braga et al. (1989), situação da antropização nas estações e parâmetros fitossociológicos nas duas épocas (1995 e 1988). Mangue de Suape, PE.

\begin{tabular}{|c|c|c|c|c|c|c|c|c|c|c|c|c|}
\hline \multirow{3}{*}{$\begin{array}{c}\text { № da } \\
\text { estação } \\
95\end{array}$} & \multirow{3}{*}{88} & \multirow{2}{*}{\multicolumn{2}{|c|}{$\begin{array}{l}\text { Situação de } \\
\text { antropização }^{1}\end{array}$}} & \multirow{3}{*}{$\begin{array}{r}\text { Área } \\
\text { basal } \\
95 \\
\end{array}$} & \multirow{2}{*}{\multicolumn{2}{|c|}{ Densidade }} & \multicolumn{3}{|c|}{ Diâmetro } & \multicolumn{3}{|c|}{ Altura } \\
\hline & & & & & & & \multirow{2}{*}{$\begin{array}{c}\text { máximo } \\
95 \\
\end{array}$} & \multirow{2}{*}{\multicolumn{2}{|c|}{$\begin{array}{rr} & \text { médio } \\
95 & 88 \\
\end{array}$}} & \multicolumn{2}{|c|}{ máxima } & \multirow{2}{*}{$\begin{array}{c}\text { média } \\
95 \\
\end{array}$} \\
\hline & & 95 & 88 & & 95 & 88 & & & & 95 & 88 & \\
\hline & & & & $\mathrm{m}^{2} / \mathrm{ha}$ & planta/ha & & & -cm------ & & ---- & $---m$ & ------- \\
\hline 1 & 1 & PA & PA & $20,8 c^{4}$ & $917 b$ & 1700 & $24 b$ & $16,4 \mathrm{~b}$ & 18,9 & $18 \mathrm{a}$ & 18 & $16,3 \mathrm{a}$ \\
\hline 2 & 6 & PA & PA & $60,8 \mathrm{a}$ & $1433 b$ & 1800 & $34 a$ & $22,4 a$ & 4,5 & $17 \mathrm{ab}$ & 15 & $14,2 \mathrm{ab}$ \\
\hline 3 & $\mathrm{Na}^{3}$ & $\mathrm{PA}$ & PA & $44,5 b$ & $1450 \mathrm{~b}$ & $\mathrm{Na}$ & $36 \mathrm{a}$ & $18,4 \mathrm{ab}$ & $\mathrm{Na}$ & $12 \mathrm{c}$ & $\mathrm{Na}$ & $11,4 b c$ \\
\hline 4 & 2 & PA & PA & $13,0 \mathrm{c}$ & $1600 \mathrm{~b}$ & 1600 & $19 b$ & $7,1 \mathrm{c}$ & 13,6 & $15 b$ & 14 & $7,7 \mathrm{~cd}$ \\
\hline 5 & 5 & PA & PA & $12,7 \mathrm{c}$ & $4066 \mathrm{a}$ & 1100 & $12 \mathrm{c}$ & $5,7 \mathrm{c}$ & 4,5 & $12 \mathrm{c}$ & 10 & $6,9 \mathrm{~d}$ \\
\hline 6 & $\mathrm{Na}$ & PA & PA & $17,0 \mathrm{c}$ & $5683 a$ & $\mathrm{Na}$ & $13 c$ & $5,6 \mathrm{c}$ & $\mathrm{Na}$ & $10 \mathrm{c}$ & $\mathrm{Na}$ & $6,7 d$ \\
\hline $\mathbf{M}^{2}$ & & & & $28,1 \mathrm{~A}$ & $2525 \mathrm{C}$ & & $23 \mathrm{~A}$ & $12,6 \mathrm{~A}$ & & $14 \mathrm{~A}$ & & $10,5 \mathrm{~A}$ \\
\hline 7 & 4 & MA & PA & $15,2 \mathrm{ab}$ & $5766 \mathrm{ab}$ & 4700 & $10 \mathrm{a}$ & $5,4 \mathrm{a}$ & 10,2 & $14 \mathrm{a}$ & 14 & $8,2 \mathrm{a}$ \\
\hline 8 & $\mathrm{Na}$ & MA & PA & $19,0 \mathrm{a}$ & $6550 \mathrm{a}$ & $\mathrm{Na}$ & $13 a$ & $5,0 \mathrm{ab}$ & $\mathrm{Na}$ & $8 \mathrm{a}$ & $\mathrm{Na}$ & $5,0 \mathrm{~b}$ \\
\hline 9 & 3 & MA & PA & $4,3 \mathrm{c}$ & $2767 \mathrm{c}$ & 2100 & $8 \mathrm{a}$ & $3,7 b$ & 6,8 & $9 a$ & 10 & $4,3 b$ \\
\hline 10 & 7 & MA & RI & $7,0 \mathrm{bc}$ & $5450 \mathrm{abc}$ & 6440 & $10 \mathrm{a}$ & $3,6 b$ & 1,7 & $10 \mathrm{a}$ & 6 & $6,4 \mathrm{ab}$ \\
\hline M & & & & $11,4 \mathrm{~B}$ & 5133B & & $10 \mathrm{~B}$ & $4,4 \mathrm{~B}$ & & $10 \mathrm{~B}$ & & $6,0 \mathrm{~B}$ \\
\hline 11 & $\mathrm{Na}$ & RI & Aterrada & $0,5 b$ & $1150 \mathrm{~b}$ & $\mathrm{Na}$ & $4 a$ & $2,1 \mathrm{a}$ & $\mathrm{Na}$ & $2 b$ & $\mathrm{Na}$ & $1,9 \mathrm{~b}$ \\
\hline 12 & $\mathrm{Na}$ & RI & Alagada & $3,8 \mathrm{a}$ & $6416 \mathrm{a}$ & $\mathrm{Na}$ & $9 a$ & $2,3 a$ & $\mathrm{Na}$ & $5 a$ & $\mathrm{Na}$ & $2,2 \mathrm{ab}$ \\
\hline 13 & $\mathrm{Na}$ & RI & Alagada & $2,6 a$ & 3366ab & $\mathrm{Na}$ & $8 a$ & $2,7 \mathrm{a}$ & $\mathrm{Na}$ & $4 \mathrm{a}$ & $\mathrm{Na}$ & $2,4 \mathrm{a}$ \\
\hline M & & & & $2,3 \mathrm{C}$ & $3644 \mathrm{C}$ & & $7 \mathrm{~B}$ & $2,4 \mathrm{~B}$ & & $4 \mathrm{C}$ & & $2,2 \mathrm{C}$ \\
\hline 14 & 8 & RA & RI & $16,0 \mathrm{a}$ & $7150 \mathrm{a}$ & 5240 & $11 \mathrm{a}$ & $4,4 \mathrm{a}$ & 1,8 & $10 \mathrm{a}$ & 8 & $5,4 \mathrm{a}$ \\
\hline 15 & $\mathrm{Na}$ & RA & RI & $13,9 a$ & $11850 \mathrm{a}$ & $\mathrm{Na}$ & $12 \mathrm{a}$ & $3,5 b$ & $\mathrm{Na}$ & $11 \mathrm{a}$ & $\mathrm{Na}$ & $6,6 a$ \\
\hline M & & & & $15,0 \mathrm{~B}$ & $9500 \mathrm{~A}$ & & $12 \mathrm{~B}$ & $4,0 \mathrm{~B}$ & & $10 \mathrm{~B}$ & & $6,0 \mathrm{~B}$ \\
\hline
\end{tabular}

1 - PA = pouco antropizada; $M A=$ muito antropizada; $R A=$ regeneração antiga; $R I=$ regeneração inicial ${ }^{2}$ - $M=$ média das estações na situação de antropização, em $1995 ;{ }^{3}$ - Na = não amostrada; ${ }^{4}$ - médias, na mesma coluna, dentro de cada situação de antropização de 1995, seguidas pela mesma letra minúscula e das situações de antropização seguidas pela mesma letra maiúscula não são significativamente diferentes pelo teste de Tukey a $5 \%$ de probabilidade.

Tabela 2. Parâmetros fitossociológicos de Rhizophora mangle (Rm), Laguncularia racemosa (Lr), Avicennia schaueriana (As) e Avicennia germinans (Ag) em 15 estações de amostragem no mangue de Suape, Pe.

\begin{tabular}{|c|c|c|c|c|c|c|c|c|c|c|c|c|}
\hline \multirow[t]{2}{*}{ Estação } & \multirow{2}{*}{$\mathrm{Rm}$} & \multicolumn{3}{|c|}{ Densidade relativa } & \multicolumn{4}{|c|}{ Área basal relativa } & \multirow[b]{2}{*}{$\mathrm{Rm}$} & \multicolumn{3}{|c|}{ IVI } \\
\hline & & $\mathrm{Lr}$ & As & $\mathrm{Ag}$ & $\mathrm{Rm}$ & $\mathrm{Lr}$ & As & $\mathrm{Ag}$ & & $\mathrm{Lr}$ & As & $\mathrm{Ag}$ \\
\hline \multicolumn{13}{|c|}{$\%$} \\
\hline 1 & 100 & 0 & 0 & 0 & 100 & 0 & 0 & 0 & 100 & 0 & 0 & 0 \\
\hline 2 & 100 & 0 & 0 & 0 & 100 & 0 & 0 & 0 & 100 & 0 & 0 & 0 \\
\hline 3 & 100 & 0 & 0 & 0 & 100 & 0 & 0 & 0 & 100 & 0 & 0 & 0 \\
\hline 4 & 26 & 62 & 7 & 5 & 87 & 10 & 1 & 2 & 53 & 35 & 9 & 3 \\
\hline 5 & 0 & 97 & 3 & 0 & 0 & 89 & 11 & 0 & 0 & 87 & 13 & 0 \\
\hline 6 & 28 & 38 & 34 & 0 & 27 & 42 & 31 & 0 & 31 & 37 & 32 & 0 \\
\hline 7 & 0 & 95 & 0 & 5 & 0 & 98 & 0 & 2 & 0 & 86 & 0 & 14 \\
\hline 8 & 16 & 70 & 0 & 14 & 9 & 48 & 0 & 43 & 20 & 56 & 0 & 24 \\
\hline 9 & 0 & 60 & 1 & 39 & 0 & 80 & 3 & 17 & 0 & 62 & 3 & 34 \\
\hline 10 & 5 & 95 & 0 & 0 & 18 & 82 & 0 & 0 & 23 & 77 & 0 & 0 \\
\hline 11 & 100 & 0 & 0 & 0 & 100 & 0 & 0 & 0 & 100 & 0 & 0 & 0 \\
\hline $12^{1}$ & 1 & 89 & 7 & 0 & 2 & 80 & 16 & 0 & 9 & 72 & 15 & 0 \\
\hline 13 & 1 & 88 & 6 & 5 & 26 & 58 & 13 & 3 & 19 & 62 & 13 & 6 \\
\hline 14 & 1 & 99 & 0 & 0 & 1 & 99 & 0 & 0 & 5 & 95 & 0 & 0 \\
\hline 15 & 1 & 99 & 0 & 0 & 1 & 99 & 0 & 0 & 5 & 95 & 0 & 0 \\
\hline
\end{tabular}


densidade total) e um aumento na das outras espécies ( $R$. mangle, de 4 a 11\%; A. germinans, de 2,5 a 4,7\%; e $A$. schauerianna, de 0,6 a $0,9 \%$ ). Comparando-se estação por estação, entre as datas, também houve poucas mudanças, exceto em uma das estações pouco antropizadas (estação 4). Por esta semelhança de resultados, não são repetidos neste trabalho os dados de distribuição obtidos por Braga et al. (1989). As duas estações amostradas em 1988 que estavam em começo de regeneração (estações 10 e 14), continuaram com populações quase exclusivas de L. racemosa. Também as estações 12, 13 e 15, não amostradas em 1988 e em regeneração inicial ou antiga em 1995, tiveram populações quase exclusivas de L. racemosa. Mas isto não quer dizer que esta espécie seja pioneira nas áreas perturbadas porque a estação 11 , em regeneração inicial em 1995, teve uma população exclusiva de $R$. mangle. Aparentemente, a regeneração se deu com as mesmas espécies presentes nas áreas antes da perturbação.

Das seis estações pouco antropizadas (PA), a metade era povoada exclusivamente por $R$. mangle mas $L$. racemosa predominou em outras duas e, na sexta, as densidades relativas foram quase iguais entre estas duas espécies e $A$. schauerianna. Assim, parece que as espécies ora mesclam-se em proporções variadas de indiví- duos, ora aparecem formando aglomerados de uma única população, e a interferência humana não tem levado a mudanças grandes nesta distribuição. Nas únicas duas estações com distribuições menos concentradas (estações 6 e 8), as proporções de densidade de cada espécie foram semelhantes às de área basal e IVI (Tab. 3). Portanto, no restante do trabalho, as análises de parâmetros darão ênfase aos totais das parcelas, só considerando as contribuições de cada espécie para ressaltar pontos específicos.

As seis estações pouco antropizadas deveriam servir como padrão de referência para comparação dos efeitos da antropização. Elas foram escolhidas pela ausência de evidências de corte de plantas, pelo seu histórico segundo os moradores das vizinhanças e pelo padrão de imagens de satélite em 1988 e 1995 (Souza 1996). O grupo destas seis estações destaca-se dos outros três grupos mais antropizados pela distribuição significativamente diferente $(\mathrm{p}<0,01)$ das alturas e diâmetros das plantas, com maior proporção de plantas de grande porte (Fig. 2 e 3 ) e pelas maiores médias de altura, diâmetro e áreas basal, e menor densidade média. Entretanto, entre si, elas mostram diferenças significativas nos parâmetros de estrutura, com densidades variando de 917 a 5683 plantas/ha, áreas basais de 12,7 a $60,8 \mathrm{~m}^{2} /$ ha, diâmetros médios e máximos

Tabela 3. Situação de antropização (SA), plântulas (PL) presentes (S) ou ausentes (N) e densidade (planta/ha) por classes de diâmetro do caule, em estações de amostragem em Suape, PE, em 1995 (este trabalho) e em 1988 (Braga et al. 1989).

\begin{tabular}{|c|c|c|c|c|c|c|c|c|c|c|}
\hline \multirow[t]{3}{*}{ Estação } & \multicolumn{5}{|c|}{95} & \multicolumn{5}{|c|}{88} \\
\hline & \multirow[t]{2}{*}{ SA } & \multirow[t]{2}{*}{ PL } & \multicolumn{3}{|c|}{ Diâmetro $(\mathrm{cm})$} & \multirow[t]{2}{*}{ SA } & \multirow[t]{2}{*}{ PL } & \multicolumn{3}{|c|}{ Diâmetro $(\mathrm{cm})$} \\
\hline & & & $<2,5$ & $>2,5$ & $>10$ & & & $<2,5$ & $>2,5$ & $>10$ \\
\hline 1 & PA & $\mathrm{S}$ & 0 & 119 & 798 & PA & S & 0 & 189 & 1511 \\
\hline 2 & PA & $\mathrm{N}$ & 0 & 67 & 1366 & PA & $\mathrm{S}$ & 0 & 1080 & 720 \\
\hline 4 & PA & $\mathrm{S}$ & 432 & 800 & 368 & $\mathrm{PA}$ & S & 0 & 376 & 1224 \\
\hline 5 & PA & $S$ & 216 & 3701 & 150 & $\mathrm{PA}$ & $\mathrm{S}$ & 0 & 1100 & 0 \\
\hline 7 & MA & $\mathrm{S}$ & 398 & 5369 & 0 & $\mathrm{PA}$ & $\mathrm{N}$ & 1410 & 2538 & 752 \\
\hline 9 & MA & $\mathrm{N}$ & 1110 & 1657 & 0 & PA & $\mathrm{N}$ & 0 & 1596 & 504 \\
\hline 10 & MA & $S$ & 1548 & 3848 & 54 & RI & $S$ & 5815 & 625 & 0 \\
\hline 14 & RA & $\mathrm{S}$ & 286 & 6799 & 64 & RI & $S$ & 4679 & 534 & 0 \\
\hline
\end{tabular}

1 - PA = pouco antropizada; $\mathrm{MA}=$ muito antropizada RA = regeneração antiga; $\mathrm{RI}=$ regeneração inicial 


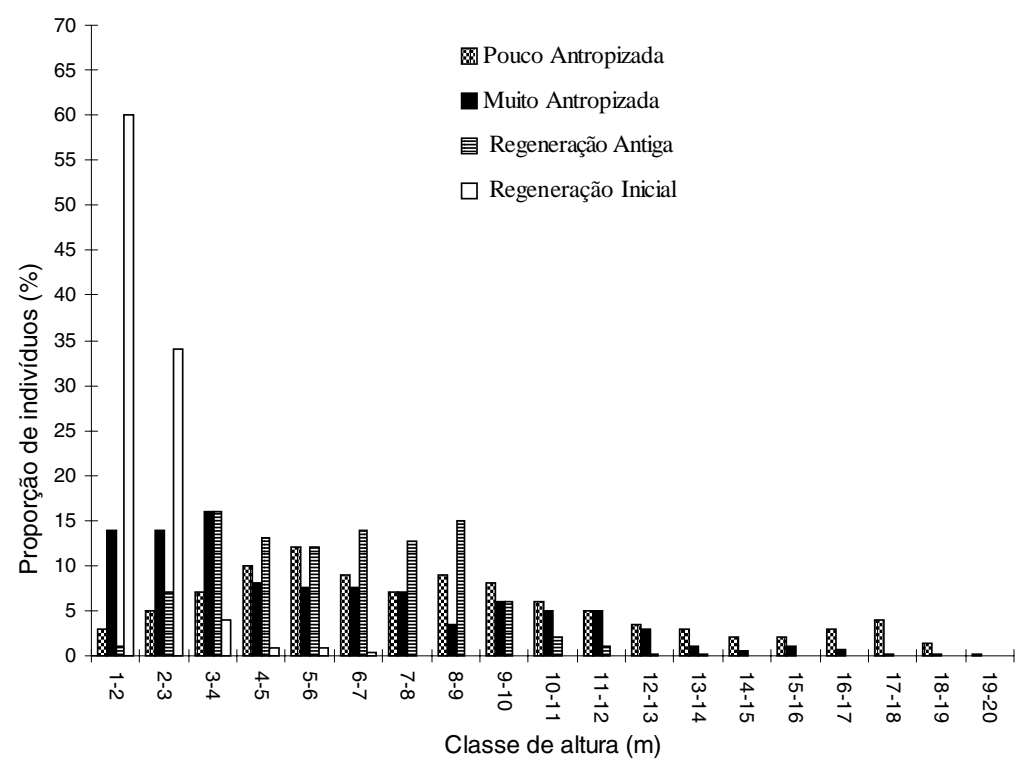

Figura 2. Distribuição do número de indivíduos por classes de altura, a intervalo fixo de $1 \mathrm{~m}$ (fechado à esquerda e aberto à direita), em áreas com diferentes situações de antropização, no mangue de Suape - PE

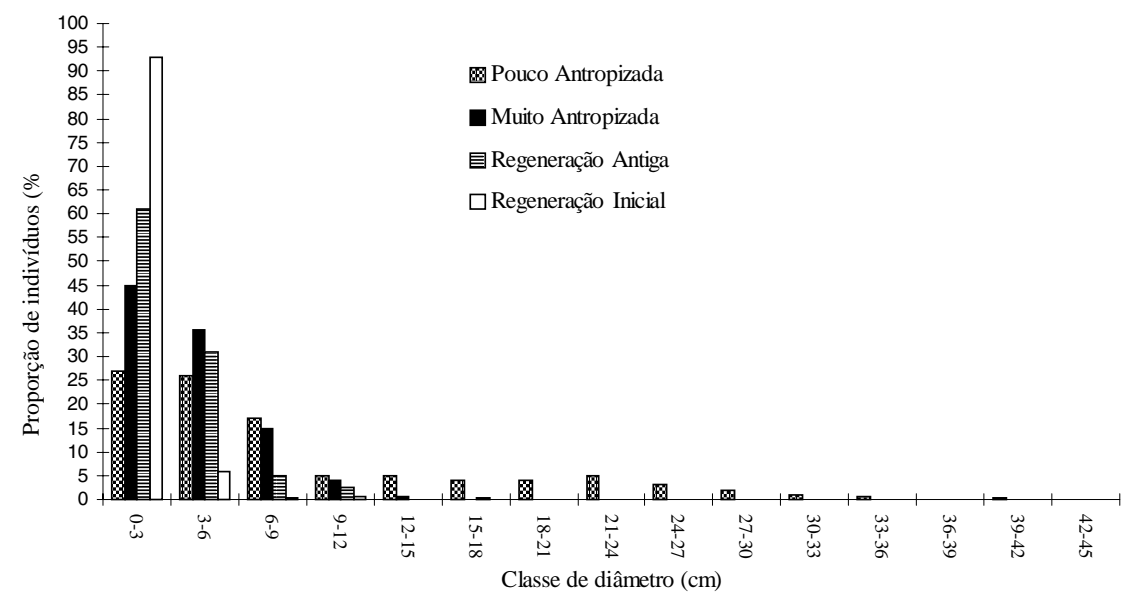

Figura 3. Distribuição do número de indivíduos por classes de diâmetro, a intervalo fixo de $3 \mathrm{~cm}$ (fechado à esquerda e aberto à direita), em áreas com diferentes situações de antropização, no mangue de Suape - PE.

de 5,6 a $22,4 \mathrm{~cm}$ e de 12 a $36 \mathrm{~cm}$ e alturas médias e máximas de 6,7 a $16,3 \mathrm{~m}$ e de 10 a $18 \mathrm{~m}$. Variações na densidade de 890 a 8870 plantas/ ha e de área basal de 5,8 a $33,0 \mathrm{~m}^{2} /$ ha foram referidas para manguezais do nordeste na revisão de Sampaio (1996), mas alguns dos trabalhos não descreveram a situação de antropização das áreas estudadas, dificultando a comparação. As densidades em Suape estavam na faixa referida mas as áreas basais atingiram valores mais altos. Mesmo fora do nordeste, áreas basais semelhantes ao maior valor encontrado não são comuns (Medeiros 1996). As alturas e os diâmetros máximos, em Suape, foram semelhantes aos registrados por Sampaio, (1996) para os manguezais nordestinos. Parte da variação entre estações pode ser atribuída à espécie predominante. As estações com predominância de $R$. mangle tiveram as menores densidades e os indivíduos de maior porte. Mas uma parte da vari- 
ação deve ser inerente às diferenças de local, e a comparação com os dados de 1988 indica que alguma variação pode ter vindo de perturbações nas áreas, não detectadas no campo e não registradas ou não declarado pelos moradores.

Algumas das mudanças entre 1988 e 1995 foram grandes o suficiente para levantar a dúvida quanto à possibilidade de sua ocorrência por processos naturais. $\mathrm{Na}$ estação 2, a densidade decresceu um pouco mas a área basal teve um enorme acréscimo, atingindo um valor absoluto alto $\left(60,8 \mathrm{~m}^{2} / \mathrm{ha}\right)$ para qualquer formação vegetal (Sampaio 1996). Realmente, as parcelas estavam na área de bosque com o maior porte encontrado em Suape. O diâmetro médio calculado em 1988 foi muito inferior ao de 1995 e a distribuição de diâmetros mostra uma inversão de classes com o tempo, de predominância na classe de 2,5 a $10 \mathrm{~cm}$, em 1988 , a uma maioria grande de plantas na classe com mais de $10 \mathrm{~cm}$, em 1995. É possível que as plantas tenham tido este crescimento muito além do crescimento médio, como nenhuma outra estação. Em plantas de mangue o crescimento médio é de menos de $1 \mathrm{~cm}$ de diâmetro por ano (Cintrón \& Schaeffer-Novelli 1983). É possível também que tenha havido erro no registro dos diâmetros em 1988 mas o diâmetro médio é consistente com a distribuição por classes de diâmetro. É interessante registrar que em nenhuma das parcelas da estação, em 1995, havia plântulas, talvez impedidas de se estabelecer pela pouca luminosidade que atingia a superfície do sedimento.

Na estação 4 ocorreu o inverso da estação 2: o diâmetro médio reduziu-se a quase a metade do de 1988 e o número de plantas com diâmetro maior que $10 \mathrm{~cm}$ reduziu-se a quase um terço do de 1988. Neste caso, ou um número grande de plantas adultas morreu naturalmente neste período, o que é pouco provável, ou elas foram cortadas. Também esta estação foi a única que teve uma mudança considerável nas proporções de indivíduos das espécies, com redução do número de plantas de $R$. mangle e aumento das de $L$. racemosa. Estas mudanças in- dicam que a área deve ter sofrido corte seletivo das plantas maiores de $R$. mangle, possivelmente já há alguns anos, de forma que tocos e outras marcas da intervenção já desapareceram. Deve ser salientado que, ao contrário das outras estações, nesta, a antropização está levando a uma regeneração maior de $L$. racemosa que de $R$. mangle e a primeira passou de uma baixa à maior densidade relativa. Não foi possível determinar a causa da baixa regeneração de $R$. mangle que, se ainda está presente com os maiores indivíduos e a maior área basal relativa (87\%), pode ir sendo gradualmente substituída.

A estação 5, como a 2, apresentam uma vegetação ainda em desenvolvimento e sua classificação, em 1988, como pouco antropizada, parece não ter considerado o porte das plantas, com ausência de indivíduos com diâmetros acima de $10 \mathrm{~cm}$ e predominância entre 2,5 e $10 \mathrm{~cm}$. Desde então, algumas plantas ultrapassaram $10 \mathrm{~cm}$ de diâmetro e alturas, diâmetros e área basal aumentaram mas a mudança mais marcante foi o acréscimo na densidade das plantas de médio e de pequeno porte. A estação 1 teve uma pequena redução no diâmetro médio e uma queda na densidade para quase metade da anterior, principalmente nas plantas com diâmetros acima de $10 \mathrm{~cm}$. Portanto, como a estação 4, deve ter tido corte seletivo. Estes dois casos (estações 5 e 1) reforçam a conclusão de uma vegetação em Suape em constante processo de antropização, ainda que as vezes não seja aparente. Remetem, ainda, para a importante conclusão de que, sem o acompanhamento no tempo, é difícil selecionar áreas não antropizadas que sirvam como padrão de referência. A melhor forma é a manutenção de parcelas permanentes com acompanhamento periódico.

A antropização nas estações 7 a 10 (MA) era visível e o corte de plantas grandes não deve ter ocorrido apenas pouco tempo antes da amostragem. O grupo teve menor porte de plantas que as pouco antropizadas, uma conseqüência direta do corte, e maior densidade, que poderia ser uma consequiência indireta e que re- 
quer tempo para que novas plantas se instalem nos espaços abertos. Entretanto, a comparação de grupos mascara a presença de estações com esta antropização visível e que tiveram valores de parâmetros semelhantes aos de estações consideradas pouco antropizadas. Só o acompanhamento no tempo permite confirmar as mudanças nos valores dos parâmetros indicadas pelas marcas de corte de plantas. Os parâmetros isolados também não permitem uma separação clara deste grupo (MA) e dos em regeneração antiga (RA) e inicial (RI) mas o conjunto permite destacar os grupos e as distribuições de alturas e diâmetros foram significativamente diferentes (todas as comparações com $\mathrm{p}<0,01$, exceto o par MA e RA com $\mathrm{p}<0,05$ para altura e não significativo para diâmetro). As alturas, a área basal e a densidade foram maiores que as de RI e a densidade menor que a de RA.

Nas estações 7 e 9, o corte seletivo resultou em decréscimo de quase $50 \%$ nos diâmetros médios e eliminação total dos indivíduos com mais de $10 \mathrm{~cm}$ de diâmetro. Apesar do corte, a vegetação na estação 7 ainda tinha uma área basal razoável, 15,2 $\mathrm{m}^{2} / \mathrm{ha}$, indicando que teria um grande porte em 1988, e parecia já ter uma certa recuperação, com aumento na densidade das plantas de porte médio e presença de plântulas, que estavam ausentes em 1988. Para que os cortes já tivessem tido efeito na densidade, deveriam vir ocorrendo há algum tempo. Na estação 9, a ausência de plântulas tanto em 1988 quanto em 1995 e a presença, em 1995, de plantas na menor classe de diâmetro $(<2,5 \mathrm{~cm})$, quando não havia nenhuma em 1988, sugerem um estabelecimento intermitente de plantas. $\mathrm{O}$ efeito do corte nas estações com muita antropização fica nítido quando as proporções de plantas nas diferentes classes de altura e de diâmetro são comparadas com as das estações com pouca antropização: as proporções são menores nas classes de maior altura e de maior diâmetro e maiores nas classes abaixo de $4 \mathrm{~m}$ e de $6 \mathrm{~cm}$. A estação 10, também muito antropizada (MA), exemplifica um outro caso, o de corte em uma vegetação ainda em re- cuperação. Em 1988, foi classificada como em regeneração e até 1995 o diâmetro médio mais que dobrou e também aumentaram a altura máxima e as densidades das plantas de grande e médio porte. Não fossem as marcas de corte recente poderia ter sido classificada como em regeneração antiga (RA). Comprovando o contínuo processo de perturbações em Suape, a área desta estação foi alagada logo após a execução das medidas fitossociológicas.

Todos os casos discutidos até agora, inclusive os classificados como pouco antropizados (PA), exemplificam a antropização por corte seletivo de plantas e diferem da antropização mais radical, por aterro ou alagamento, que caracterizam as outras estações discutidas mais adiante. $\mathrm{O}$ corte seletivo altera pouco alguns dos parâmetros medidos. Os valores de altura e diâmetro máximos podem não ser alterados, pela própria preservação dos indivíduos representados ou pela existência de indivíduos semelhantes. A densidade total reduz-se logo após o corte mas tende a aumentar depois, até para valores superiores aos de antes do corte, com o estabelecimento de muitas plantas novas e pequenas nos espaços vazios abertos com a retirada das plantas grandes cortadas. Diâmetros e alturas médias tendem a decrescer com o corte, quase sempre de plantas com porte acima da média, mas o efeito pode ser variado, dependendo do porte das plantas retiradas, do estádio de crescimento da vegetação por ocasião do corte e do tempo após o corte em que a medida é feita, junto com a regeneração da vegetação no período, que também influem na densidade. A área basal total é o parâmetro simples mais sensível ao corte mas a melhor medida é a mudança no número de indivíduos por classes de diâmetro e por classes de altura.

A situação das estações que foram alagadas ou aterradas (RI e RA) é muito distinta das com corte seletivo porque todas ou a quase totalidade das plantas existentes foram mortas. As estações 11 a 13 (RI) ilustram o caso desta destruição recente, com regeneração em diferentes es- 
tádios iniciais. Como a destruição foi posterior a 1988 não há dados comparativos desta época. Alturas e áreas basais foram baixas, inferiores tanto às das estações pouco quanto às das estações muito antropizadas (PA e MA), mesmo com a variabilidade alta destas. A grande maioria das plantas tinha menos de $3 \mathrm{~m}$ de altura e de $3 \mathrm{~cm}$ de diâmetro. Já as densidades não permitem separar grupos e tiveram faixa ampla, semelhante à das estações pouco antropizadas. Entre as estações de regeneração inicial, os valores mais baixos de todos os parâmetros, incluindo densidade, foram determinados na estação aterrada, indicando uma recuperação lenta após esta perturbação. Este grupo de regeneração inicial difere significativamente do grupo de regeneração mais antiga em todos os parâmetros, exceto os de diâmetros médio e máximo.

As duas estações em áreas que em 1988 já estavam em processo de recuperação (RA) e que não apresentavam sinais de cortes recentes (estações 14 e 15) dão uma medida da velocidade de recuperação da vegetação. A estação 14 (única com dados em 1988) teve aumentos em todos os parâmetros fitossociológicos. O aumento em densidade, que alcançou um dos valores mais altos de Suape (7150 plantas/ha), indica que o maior número de plantas por área é atingido alguns anos após o início da recuperação, devendo levar mais alguns anos até que a competição elimine os indivíduos mais fracos e a densidade caia aos valores em torno de 1000 plantas/ha, encontrados nos locais pouco antropizados. A densidade da estação 15, a mais alta encontrada (11850 plantas/ ha), confirma esta observação. As densidades altas contribuíram para a obtenção de áreas basais totais semelhantes às de algumas estações pouco antropizadas, compensando diâmetros médios e máximos ainda abaixo dos das parcelas pouco antropizadas. Alturas máximas e médias também não tinham ainda atingido valores semelhantes aos das estações pouco antropizadas. A distribuição por classes de altura mostra uma semelhança no número de plantas nas classes de 3 a 9m, com valores superiores aos das classes de 1 a $3 \mathrm{~m}$, in- dicando que o estabelecimento de plantas passou por uma fase de máximo e caiu, possivelmente pela competição quando a densidade atingiu valores altos. Já a distribuição por classes de diâmetro mostra queda progressiva desde a classe de menor diâmetro (0 a $3 \mathrm{~cm})$, indicando a presença de grande número de plantas relativamente altas e finas e sugerindo uma possível competição por luz entre elas. Apesar desta aparente queda no estabelecimento de plantas, estas estações tinham grande número de plântulas. Este resultados mostram que a regeneração completa deve levar mais que os oito anos observados.

\section{Referências bibliográficas}

ADEMA. 1984. Levantamento da flora e caracterização dos bosques de mangue do Estado de Sergipe. Aracaju. 1984. Relatório Técnico. 154p.

Amarasingle, M. D. \& Balasubraniam, S. 1992. Structural properties of two types of mangroves stands on the Northwestern Coast of Sri Lanka. Hidrobiologia 247: 17-27.

Andrade, G. O. \& Lins, R. C. 1971. Os Climas do Nordeste. In: Vasconcelos Sobrinho, J. As regiões naturais do Nordeste, o meio e a civilização. Recife, CONDEPE. p. 95-18.

Azariah, J.; Azariah, H.; Gunasekaran, S. \& Selvam V. 1992. Structure and species distribution in Coringa mangrove forest, Godavari Delta, Andhra Pradesh, India. Hydrobiologia 247: 11-16.

Blanchard, J. \& Prado, G. 1995. Natural regeneration of Rhizophora mangle in strip clearcuts in North West Ecuador. Biotropica 27(2): 160-162.

Braga, R. A. P.; Uchoa, T. M. M. \& Duarte, M. T. 1989. Impactos ambientais sobre o manguezal de SuapePE. Acta Botânica Brasilica. Anais do XL Congresso Nacional de Botânica. 3 (2): supl. 9 a 27.

Cavalcante, L. B.; Coelho, P. A.; Leça, E. E.; Luna, J. A. C.; Macêdo, S. J. \& Paranaguá, M. N. 1980. Condiciones ecológicas en el area de Suape (Pernambuco-Brasil). Memorias del Seminario sobre el Ecosistema de Manglares. Oficina Regional de Ciencia y Tecnologia de la UNESCO para America Latina e el Caribe, Montevideo, p. 243-256.

Cintron, G. 1987. Caracterización y manejo de áreas del mangle. In: Simpósio sobre Ecossistemas da Costa Sul e Sudeste Brasileira: Síntese dos Conhecimentos, Cananeia. Anais. São Paulo, Academia de Ciência do Estado de São Paulo, v.3, p. 77-75. 
Cintron, G. \& Schaeffer- Novelly, Y. 1983. Introdución a la ecologia del manglar. Montevideo, UNESCO/ ROSTLAC. 109p.

Clarke, P. J. \& Allaway, W.G. 1993. The regeneration niche of the grey mangrove (Avicennia marina): effects of salinity, light and sediment factors on establisment. Oecologia 93 : 548-556.

Damásio, E. 1980 Contribuição ao conhecimento da vegetação dos manguezais da Ilha de São Luis - MA. Ponte II. São Luis - MA - Separata Hidrobiologia Biológica 3(1): 57-76.

Dixon, P.; Robertson, A. I. \& Daniel, P. A. 1991. Structure and productivity in the Fly River estuary, Papua New Guinea. Marine Biology Austral 111(1): 147- 156.

Gomes, M. A. 1989. Composição e variação anual do fitoplâncton na plataforma continental norte de Pernambuco. Recife. Universidade Federal de Pernambuco. Dissertação de Mestrado. 124p.

Medeiros, T. C. C. 1996. Produtividade e biomassa das espécies arbóreas do manguezal do estuário do Rio Paripe, em Vila Velha, Itamaracá, PE. Recife. Universidade Federal Rural de Pernambuco. Dissertação de Mestrado. 199p.

Melo-Filho, J. A. S. 1977. Caracterização da situação atual da área programa Suape sob o ponto de vista poluição da ambiental. Recife, CONDEPE. $15 \mathrm{f}$. (Comunicação Técnica, 1).

Neumann, V. H. M. 1991. Geomorfologia e sedimentologia quaternária da área de Suape, Pernambuco (Brasil). Universidade Federal de Pernambuco. Dissertação de Mestrado. 94p.

Neumann-Leitão, S. 1994. Impactos antrópicos na comunidade zooplanctônica estuarina. Porto de Suape-PE. Brasil. São Carlos. Universidade Federal de São Carlos. Tese de Doutorado. 273p.

Pereira, S. B. 1993. Aspectos ecológicos de áreas de manguezais em Pernambuco. ANAIS da $4^{\circ}$ Reunião Anual da Sociedade Brasileira para o Progresso da Ciência. Universidade Federal de Pernambuco. p.885.

Pool, D. J.; Snedaker, S. C. \& Lugo, A. E. 1975. Structure of mangrove forest in Florida, Puerto Rico, Mexico and Costa Rica. In: Memórias do II Simpósio Latino Americano sobre Oceanografia Biológica. Cumana. p. 49-12.
Rao, M. B.; Rao, P. N.; Reddy, D. L.; Rambabu, A. V. S. \& Prasad, B. V. 1987. Ecological changes in a tropical mangrove ecosystem due to human impact. Tropical Ecology 28: 232-238.

Robertson, A. I.; Dixon, P. \& Daniel, P. A. 1991. Mangrove forest structure and productivity in Fly River estuary, Papua New Guinea. Marine Biology 111: $147-155$.

Rodal, M. J. N.; Sampaio, E. V. S. B. \& Figueiredo, M. A. 1992. Manual sobre métodos de estudo florístico e fitossociológico - ecossistema caatinga - Brasília: Sociedade Botânica do Brasil, 24p.

Sampaio, E. V. S. B. 1996. Fitossociologia. In: Sampaio, E. V. S. B; Mayo, S. I; Barbosa, M. R. V. Pesquisa Botânica Nordestina: Progresso, perspectivas. Recife, Sociedade Botânica do Brasil - Seção Regional de Pernambuco. p. 203-224.

Schaeffer-Novelli, Y. 1993. Manguezais: sistemas abertos. Revista Ecologia e Desenvolvimento. Ano 2. $\mathrm{n}^{\circ}$ 27. Ed. $3^{\circ}$ Mundo Ltda. Maio. p. 30 a 37.

Schaeffer-Novelli, Y. \& Cintron, G. 1986. Guia de estudos de áreas de manguezal: estrutura, função e flora. São Paulo: Cariban Ecological Research, $150 p+3$ apêndices.

SEMACE. 1994. Composição florística e estrutura dos bosques de mangue dos rios Ceará, Cocó e Pacoti. Fortaleza-CE. 48p.

Sielgel, S. 1975. Estatística não - paramétrica para as ciências do comportamento. São Paulo, McGraw - Hill. 350p.

Silva, C. A. R. 1991. Forest structure and biomass distribution in a red mangrove stand in Sepetiba Bay, Rio de janeiro. Revista Brasileira de Botânica 14: 21-25.

Souza, M. M. A. 1996. Variação temporal da estrutura dos bosques de mangue de Suape - PE, Recife. Universidade Federal Rural de Pernambuco. Dissertação de Mestrado. 90p.

Statsoft, G. Inc. 1995. Statistica for Windows (computer program manual). Tulsa. 